\title{
Correction to: New biogeographic distribution record of phytophagous syrphid, Eumerus vestitus Bezzi, its biosystematics, host preferences and association behavior
}

\author{
S. S. Anooj ${ }^{1}$ - V. Kalia ${ }^{1}$ • G. K. Krishna ${ }^{2,3} \cdot$ K. D. Ghorpade ${ }^{4}$
}

Published online: 27 February 2020

(C) African Association of Insect Scientists 2020

Correction to: International Journal of Tropical Insect Science (2020)

https://doi.org/10.1007/s42690-020-00100-3

In the original publication, the family name of the last author appeared incorrectly as it should have read: K. D. Ghorpade. The proper representation of the authors' names and their affiliations is published here and should be treated as definitive.

The online version of the original article can be found at https://doi.org/ 10.1007/s42690-020-00100-3

\section{S. S. Anooj \\ anooj227@gmail.com}

1 Division of Entomology, Indian Council of Agricultural Research-Indian Agricultural Research Institute, New Delhi, Delhi 110012, India

2 Department of Plant Physiology, NMIMS-School of Agricultural Sciences and Technology, Shirpur, Maharashtra 425405, India

3 Division of Plant Physiology, Indian Council of Agricultural Research-Indian Agricultural Research Institute, New Delhi, Delhi 110012, India

4 Department of Entomology, University of Agricultural Sciences, Dharward, Karnataka 580 008, India 